\title{
Investigation on the Depth of Slip Hanger Teeth Bite into Casing and the Mechanical Properties of Casing under Different Suspension Loads in Ultra-Deep Wells
}

\author{
Yong Chen - Jinjin Tan - Guoping Xiao \\ Southwest Petroleum University, School of Mechanical and Electrical Engineering, China
}

There is great difficulty in controlling the setting load of the large-size slip casing hanger in the Northwest Oilfield in China, and a reasonable setting load is of great significance. This paper studied the relationship between slip hanger bite depth and suspension load in the $\Phi 273 \mathrm{~mm}$ WE-type slip hanger in the Northwest Oilfield in China through experiment, theoretical computation, and finite element analysis. The accuracy of the finite element model was proved by comparing the finite element simulation results with the experimental bite marks on the casing surface. The study results show that the bite mark of the slip insert in the casing is deeper in the lower part of the sitting position. When the hanging load increases from $1000 \mathrm{kN}$ to $6000 \mathrm{kN}$, the maximum bite depth of the slips in the casing gradually increases with the suspension load. The residual collapse strength of the casing decreases correspondingly. When the residual collapse strength decreases to a certain value, the maximum suspension force corresponding to the bite depth of the slip insert can be obtained. Based on the finite element research results and theoretical equations, the stress distribution on the casing wall where the slips bite the deepest is obtained by derivation. The suggestions on improving the material structure of the casing under this stress were proposed. The limit of the setting load of the large-size casing wellhead for avoiding casing collapse was obtained, which is of great significance for guiding field-casing setting.

Keywords: WE-type slip hanger, suspension load, slip hanger bite depth, finite element simulation, casing

Highlights

- The relationship between slip hanger bite depth and suspension load has been studied.

- The bite depth of the slips is gradually reduced from no. 1 to no. 17 (from bottom to top) under a specific suspension load.

- The maximum circumferential squeezing stress on the inner wall of the casing is the risky section, which is subjected to the deepest bite by slip inserts.

- As the suspension load increases, the casing residual collapse strength decreases.

- Comparing the experimental result with the finite element result, shows that the two are consistent.

\section{O INTRODUCTION}

There is increasing difficulty in controlling the setting load due to increasing large-size casing tripped into deep reservoirs in the Northwest Oilfield in China. Excessive setting loads and the high-pressure and high-temperature (HPHT) conditions of reservoirs (such as $70 \mathrm{MPa}$ and $170^{\circ} \mathrm{C}$ ) will cause problems such as wellhead subsidence, and severe damage to the casing caused by slips and the sitting load is too small possibly lead to poor sealing of the casing head [1] and [2]. Tripping the liner hanger into the upper casing is completed through interaction between the liner hanger slips and the casing. The setting of the liner hanger causes variation in the initial stress distribution inside the casing. The additional circumferential stress and additional axial stress caused by slips increase the load on the casing and affect the safety performance of the casing; those beyond the original design loads significantly lessen the margin against piping failure [3]. Statistics found that there were 10 well-times of large-size deep well casings in the past two years, and 3 well-times had abnormalities during wellhead installation. Therefore, a choice of setting load to solve the above contradictions and recommended practices for the setting of large casings are of great significance.

Many efforts have been put in analysis of the force and structure of the slip hanger and casing. Li et al. [4] and Tong et al. [5] carried out the mechanical analysis of slips on the packer with statics principles and obtained the formula for calculating the normal stress on the slip insert during anchoring of the slips and. Tang et al. [6] aim at the problem of damage caused by the casing pressure on the slip after setting, the pressure-bearing law of the slip teeth under the threetooth parameters was analysed. Mohammed et al. [7] focused on factors attributing to casing failure, their failure mechanism and the resulting failure mode. The slip-casing bite model was analysed using the finite element numerical simulation method, which has been widely used in recent years. Wang et al. [8] carried out the finite element analysis of the force process of slips and improved the structural parameters of slips.

However, when the well's casing head pressure cannot be permanently bled off with a needle valve, 
the casing is said to exhibit sustained casing pressure (SCP) [9]. A cement sheath can act as a secondary barrier element in a dual barrier (elastomer seal and cement sheath) zonal isolation system. Cement is the main physical barrier able to seal fluid flow into unintended zones from the wellbore [10] and [11]; the rubber materials can be squeezed into the annulus between the hanger and the upper casing, effectively sealing the annulus, and providing an efficient twoway pressure-bearing capacity [12] to [14].

In this study, the relationship between slip insert bite depth and suspension load of the WE-type slip hanger of the Northwest Oilfield in China was studied using finite element analysis methods and theoretical computation. The limit of the setting load of the large casing wellhead for avoiding casing collapse was obtained. The formula for calculating the internal stress distribution of the risky section of the casing was derived to guide the design of the well structure and field operation.

\section{THEORETICAL ANALYTIC METHODS}

Current well-drilling and operation technologies cannot provide cost-effective solutions for emerging challenges. Based on statistics, casing deformation was observed in 38 wells out of 72 horizontal wells after hydraulic fracturing [15] and [16]. According to the field survey, there is always a section with the largest bite depth when the slip hanger holds the casing, i.e., the risky section. Lowering the $\mathrm{pH}$ value will cause an electrochemical reaction. It is common for the casing material to be exposed to the $\mathrm{H}_{2} \mathrm{~S} / \mathrm{CO}_{2}$ acid gas environment, and electrochemical reactions are prone to occur in risky sections [17] to [19].

In order to roughly clarify how the casing will be destroyed after exceeding the limit suspension load, the distribution of circumferential normal stress, radial normal stress, circumferential and radial shear stress of the dangerous section of the casing is determined by the theory of elastoplastic mechanics [20].

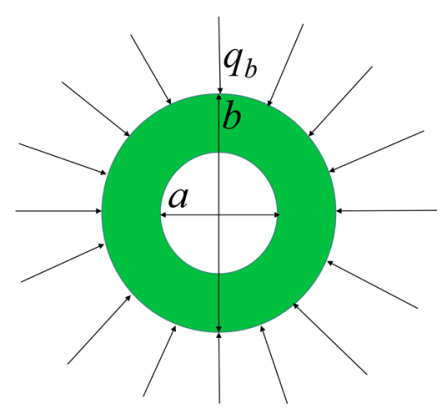

As shown in Fig. 1, the risky section of the casing is simplified as a circular ring. The outer wall of the ring is bitten by the slip inserts to produces a squeezing force. If the casing body force is neglected, the force is axisymmetric, and the stress component is written as [20]:

$$
\begin{gathered}
\sigma_{\rho}=\frac{A}{\rho^{2}}+B(1+2 \ln \rho)+2 C, \\
\sigma_{\varphi}=-\frac{A}{\rho^{2}}+B(3+2 \ln \rho)+2 C, \\
\tau_{\rho \varphi}=\tau_{\varphi \rho}=0 .
\end{gathered}
$$

Boundary conditions:

$$
\begin{gathered}
\left(\tau_{\rho \varphi}\right)_{\rho=a}=0, \\
\left(\tau_{\rho \varphi}\right)_{\rho=b}=0, \\
\left(\sigma_{\rho}\right)_{\rho=a}=0, \\
\left(\sigma_{\rho}\right)_{\rho=b}=-q_{b} .
\end{gathered}
$$

According to Eq. (3), Eqs. (4) and (5) are satisfied. Eqs. (6) and (7) are expressed as:

$$
\begin{gathered}
\frac{A}{a^{2}}+B(1+2 \ln a)+2 C=0, \\
\frac{A}{b^{2}}+B(1+2 \ln b)+2 C=-q_{b} .
\end{gathered}
$$

A compatible equation is expressed as:

$$
\left(\frac{\partial^{2}}{\partial \rho^{2}}+\frac{1}{\rho} \frac{\partial}{\partial \rho}+\frac{1}{\rho^{2}} \frac{\partial^{2}}{\partial \varphi^{2}}\right)^{2} \Phi=0,
$$

which satisfies the compatibility equation.

The balanced differential equation (casing bodyweight neglected) is expressed as:

$$
\begin{gathered}
\frac{1}{\rho} \frac{\partial \sigma_{\varphi}}{\partial \varphi}+\frac{\partial \tau_{\rho \varphi}}{\partial \rho}+\frac{2 \tau_{\rho \varphi}}{\rho}=0, \\
\frac{\partial \sigma_{\rho}}{\partial \rho}+\frac{1}{\rho} \frac{\partial \tau_{\rho \varphi}}{\partial \rho}+\frac{\sigma_{\rho}-\sigma_{\varphi}}{\rho}=0,
\end{gathered}
$$

which satisfies the balanced differential equation.

According to the displacement single value condition, $B=0$, then:

$$
A=\frac{a^{2} b^{2} q_{b}}{b^{2}-a^{2}}, \quad 2 C=\frac{-q_{b} b^{2}}{b^{2}-a^{2}}
$$

which are incorporated into Eqs. (1) and (2) and rearranged to obtain the Lame solution of casing stress:

Fig. 1. Diagram of stress on risky section of casing 


$$
\begin{gathered}
\sigma_{\rho}=-\frac{1-\frac{a^{2}}{\rho^{2}}}{1-\frac{a^{2}}{b^{2}}} q_{b}, \\
\sigma_{\varphi}=-\frac{1+\frac{a^{2}}{\rho^{2}}}{1-\frac{a^{2}}{b^{2}}} q_{b},
\end{gathered}
$$

where $\rho$ is casing radial length interval, $\rho \in[a, b]$, $\sigma_{\rho}$ casing radial normal stress, $\sigma_{\varphi}$ circumferential normal stress on casing, $\tau_{\rho \varphi}, \tau_{\varphi \rho}$ circumferential and radial shear stress, $A, B, C$ arbitrary constants, $a, b$ casing inner and outer diameters, $q_{b}$ external stress of slips on the casing, and $\Phi$ stress function.

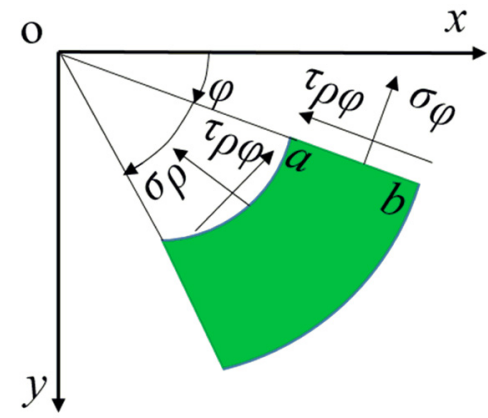

Fig. 2. Distribution of stresses in the polar coordinates

The above quantities are described in the form of polar coordinates (Fig. 2); the specific direction and size are determined according to the calculated results.

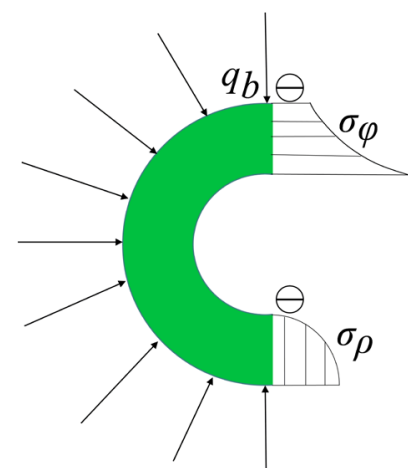

Fig. 3. Distribution of stress inside the casing radial risky section

According to derivation, $a, b$ and $q_{b}$ in expression $\sigma_{\rho}$ are all constants, and $\sigma_{\rho}$ is only positively correlated to $\mathrm{a}^{2} / \rho^{2}$. Similarly, $\sigma_{\varphi}$ is only positively correlated to $-\mathrm{a}^{2} / \rho^{2}$. According to theoretical derivation, the distribution of the radial normal stress and circumferential normal stress on the casing is obtained (Fig. 3).

\section{EXPERIMENTAL APPROACH AND PROCEDURE}

\subsection{Experimental Apparatus}

The experiment was carried out on a horizontal hydraulic experiment box, model XDL- $10000 \mathrm{kN}$, and its main technical indicators are shown in Table 1.

Table 1. Technical indexes of XDL-10000 kN horizontal hydraulic experimental chamber

\begin{tabular}{lc}
\hline Item & Parameter \\
\hline Maximum test force & $10000 \mathrm{kN}$ \\
\hline Hydraulic cylinder piston stroke & $1000 \mathrm{~mm}$ \\
\hline Stretching chuck distance up and down & $6 \mathrm{~m}$ \\
\hline Test machine space & $500 \mathrm{~mm} \times 6000 \mathrm{~mm}$ \\
\hline Machine host size & $9000 \mathrm{~mm} \times 1200$ \\
$(\mathrm{~L} \times \mathrm{W} \times \mathrm{H})$ & $\mathrm{mm} \times 800 \mathrm{~mm}$ \\
\hline Hydraulic system power & $5 \mathrm{~kW}$ \\
\hline The total weight of the machine & $9000 \mathrm{~kg}$ \\
\hline
\end{tabular}

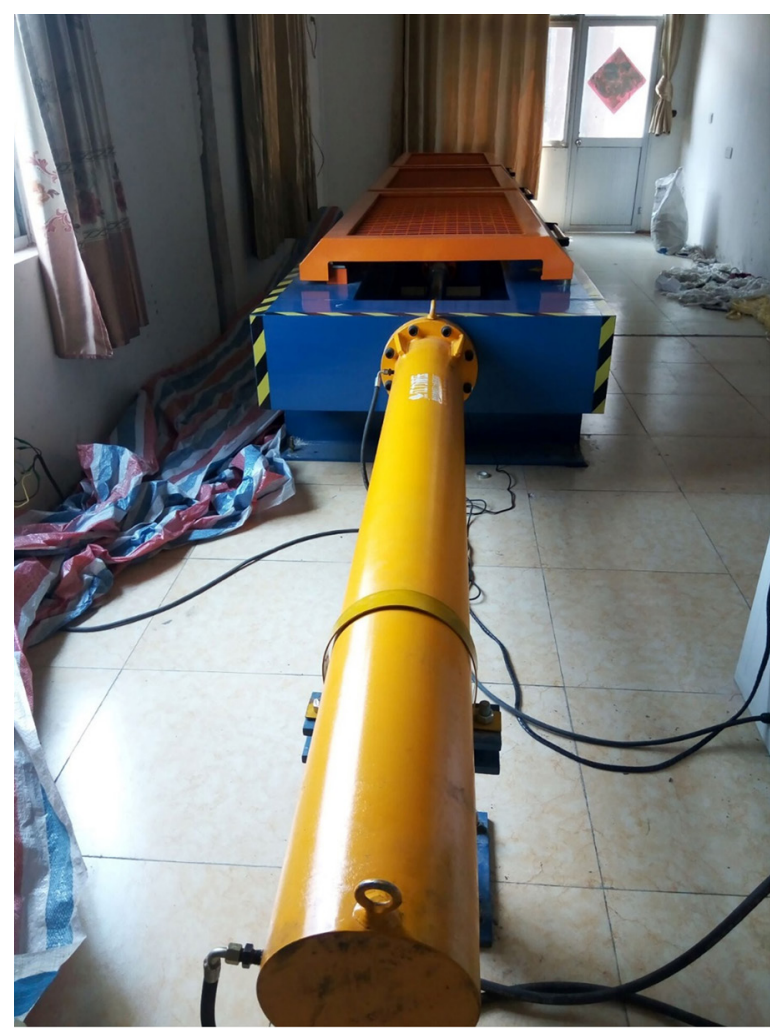

Fig. 4. Hydraulic experimental chamber

Fig. 4 shows the test machine used for casing tensile testing. The body adopts a double-frame force frame structure; a single-hydraulic cylinder is installed on the upper beam, the piston and sensor through the force frame and the upper tensile fixtures are directly connected on the specimen tensile test, 
so that the loading head structure is simplified; The reaction frame and the left and right rigid frame are connected to the main body of the testing machine; The down-stretching chuck body is connected with the cross beam on the other side of the frame. The side of the host machine is equipped with a hydraulic loading system, which adopts a low-noise hydraulic pump unit, a hydraulic valve group, and a highprecision electro-hydraulic control valve to ensure high precision, high efficiency, low noise and fast response of the system, and to realize the automatic control of loading and reversing of the test (Fig. 5).

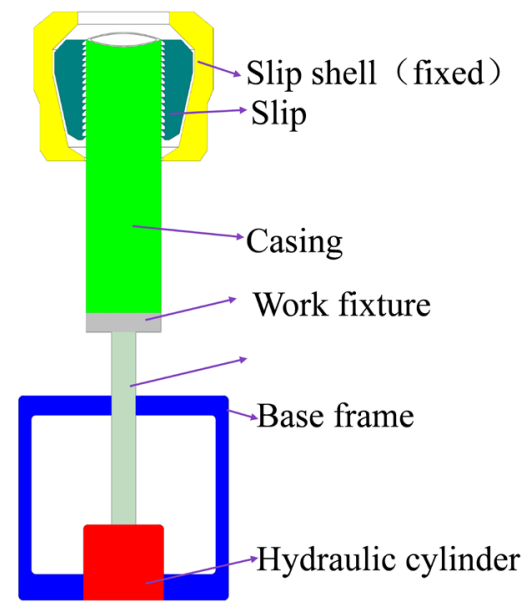

Fig. 5. The experiment schematic diagram

\subsection{Experimental Procedure}

In the experiment, the load increased by $500 \mathrm{kN}$ uniformly over time, and the axial stress on the slips simultaneously measured was plotted as shown in Fig. 6.

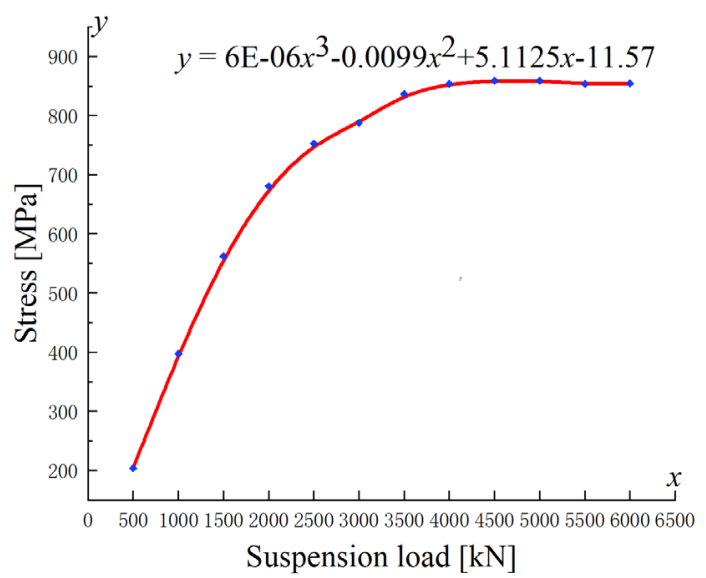

Fig. 6. Relationship between different experimental loads and maximum normal stress
As show in Fig. 6 that as the load increases, the maximum normal stress on the casing also increases, and the function fitted according to the curve is a third-order equation. It can be seen that the influence of the load on the results of the research is nonlinear.

\section{FINITE ELEMENT ANALYSIS AND MATERIAL PREPARATION}

\subsection{Structure of $\phi 273 \mathrm{~mm}$ WE-Type Slip Hanger}

In this paper, the $\phi 273 \mathrm{~mm}$ WE slip hanger commonly applied in the Northwest Oilfield in China was studied. The 3D solid structure established according to the real size is illustrated in Fig. 7.

a)

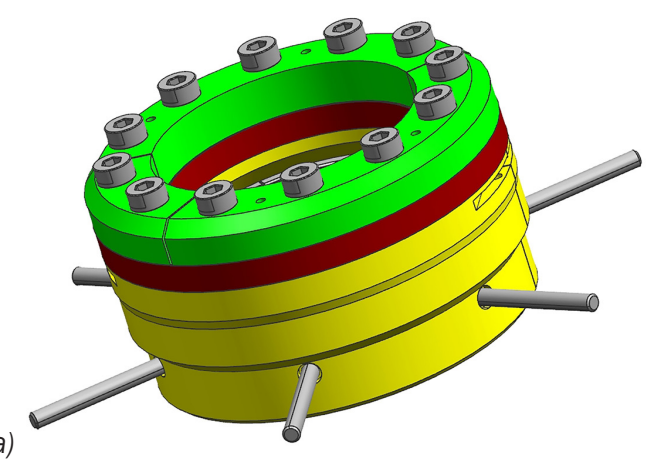

b) 7

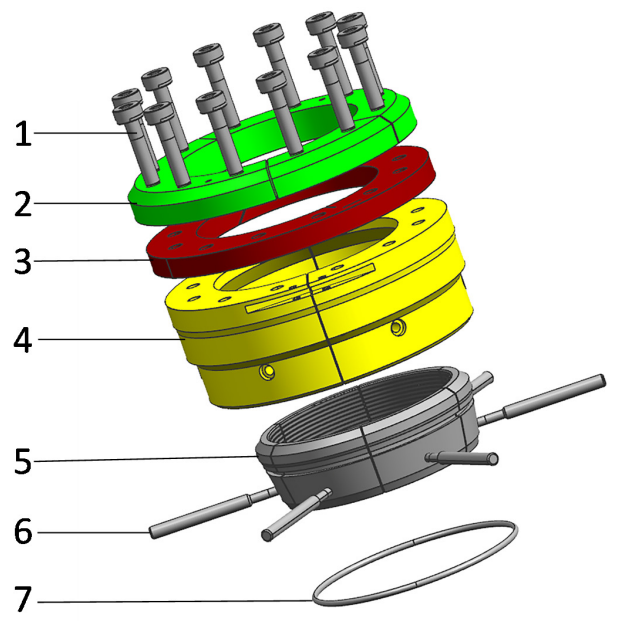

Fig. 7. a) WE-type-slip hanger assembly diagram; b) WE-type slip hanger exploded view

According to Fig. 7, the slip hanger consists of 1 hexagon socket screw; 2 pressure plate; 3 sealing ring; 4 slip shell; 5 slip teeth; 6 screw; 7 positioning block

\subsection{Working Principle and Analysis of Stress on WE-Type Slip Hanger}

The stress on the casing head slips is illustrated in Fig. 8. 
1.Casing

2. Slip insert

3. Slip shell

(slip weight is neglected)

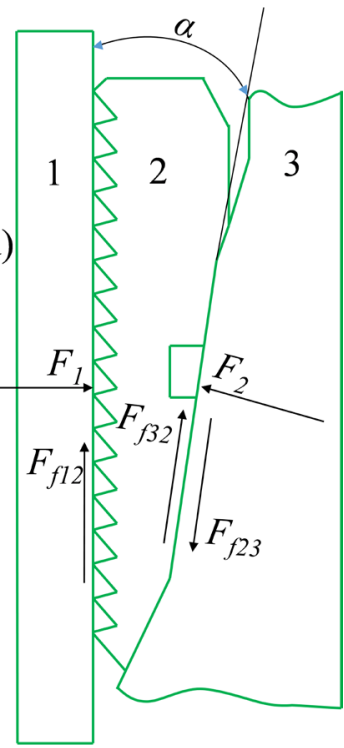

Fig. 8. Stress on slips

The process of slip bite in the casing is one of interaction between the slips and the pipe string. When Slip 2 starts to bite into Casing 1, the active force comes from the initial friction force received by the slips. The slips will hold the pipe string radially by causing reactions to the slips through amplifying them with the casing weight. In this process, the casing causes a large vertical gravitational acceleration under the action of the huge suspension load, and this causes the mutual friction between the casing and the slip insert tip, which propels the slip to move downward along Shell 3 until the slips cannot slide. Then, the slips are in direct contact with the slip shell through the inclined plane, and the casing moves downward to squeeze the slips, which remain in the same position by the support of the slip shell. The slip teeth are squeezed into the casing to generate a squeezing force; thus, sufficient friction is created to reach a mechanical equilibrium on the casing. If the suspension weight of the downhole casing increases, the slips continue to bite into the casing due to greater squeezing force until a new balance is reached, and the safe suspension of the casing is realized.

According to Fig. 8, the slips are subjected to the squeezing force and the frictional force of the casing and the slip shell; enough friction is generated by the bite of the slip teeth into the casing to balance the casing gravity. Therefore, for slips, we obtain according to the principle of static balance:

$$
\begin{aligned}
& F_{1}+F_{f 32} \sin \alpha=F_{2} \cos \alpha, \\
& F_{2} \sin \alpha+F_{f 32} \cos \alpha=G,
\end{aligned}
$$

where $F_{1}$ is the supporting force of the casing on the slips $[\mathrm{N}], F_{2}$ the supporting force of the slip shell on the slips [N], $F_{f 32}$ the frictional force of slip shell on the slips $[\mathrm{N}], F_{f 12}$ the friction force of the casing against the slips $[\mathrm{N}], F_{f 23}$ the friction force of the slips against the slip shell $[\mathrm{N}], \alpha$ the slip cone angle $\left[{ }^{\circ}\right]$, and $G$ the casing weight [N].

\subsection{Establishment of Finite Element Model of WE-Type Slip Hanger}

The parameters of material properties input in the process of finite element modelling are listed in Table 2.

The model's geometric dimensions, loads, and boundary conditions are symmetrical with regard to the axis. An axisymmetric finite element model is established to reduce the computational effort. Full constraints are imposed on the slip shell, and the suspension weight is simplified as an axial load acting on the casing. Finite element analysis (FEA) is an established standard procedure in many areas of numerical strength analysis [21] and [22]. According to the structure of the WE-type casing hanger and casing, assumptions are also made as follows to simplify the analysis model:

(1) The material is an elastoplastic body with isotropic and homogeneous properties;

(2) The effect of ovality and wall thickness unevenness of casing hanger and casing is neglected;

(3) The effect of the error in wellhead suspension installation is neglected.

A finite element model of the slips holding the casing was established according to the real hanger structure, and the model was meshed, as shown in Figs. 9 and 10. Mesh refinement of the slip inserts, the

Table 2. Parameters of material properties of metal components

\begin{tabular}{lcccccc}
\hline Component & Material & $\begin{array}{c}\text { Density } \\
{\left[\mathrm{kg} / \mathrm{m}^{3}\right]}\end{array}$ & $\begin{array}{c}\text { Young's modulus } \\
{[\mathrm{MPa}]}\end{array}$ & $\begin{array}{c}\text { Poisson's ratio } \\
\text { Yield strength } \\
{[\mathrm{MPa}]}\end{array}$ & $\begin{array}{c}\text { Tensile strength } \\
{[\mathrm{MPa}]}\end{array}$ \\
\hline Slips & 718 & 7850 & 249350 & 0.3 & 980 & 1550 \\
\hline Slip bowl & 30CrMo & 7850 & 249350 & 0.3 & 785 & 930 \\
\hline Casing head & 30CrMo & 7850 & 249350 & 0.3 & 517 & 655 \\
\hline
\end{tabular}


casing outer wall, the clip side surface, and the inner surface of the slip shell was carried out to obtain the accurate calculation results of contact between slips and the casing outer wall and between the slip side surface and the slip shell conical surface.

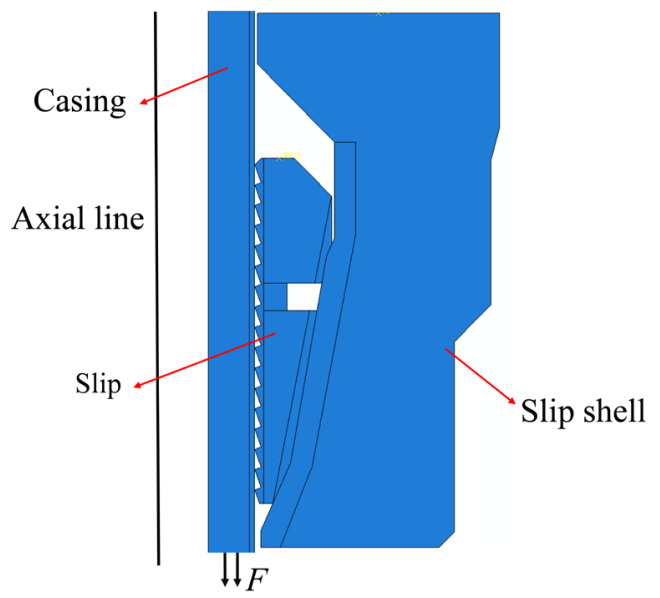

Fig. 9. Finite element model of slips holding the case

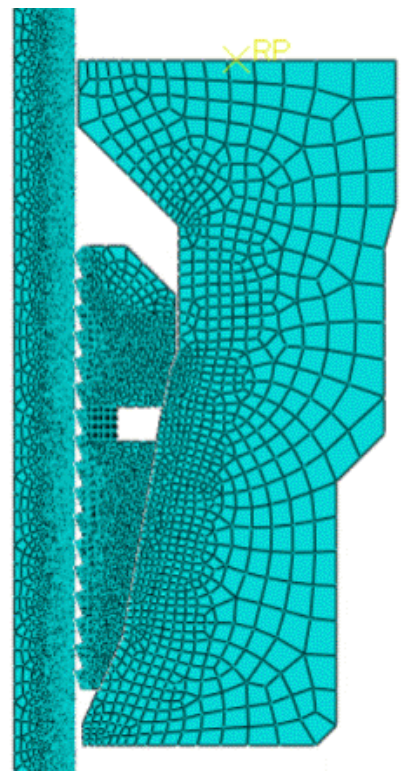

Fig. 10. Meshing of model

\section{RESULTS AND DISCUSSION}

\subsection{Comparison of Results}

The finite element simulation results are compared with the experimental bite marks on the casing surface to verify the correctness of the analysis results, as shown in Fig. 11.

According to Fig. 11, when the slip is holding the casing, the slip teeth squeeze the casing and bite into the casing wall. The slip teeth leave a bite mark with a clear texture on the casing surface. When the suspension load reaches a certain value, plastic deformation occurs on the bite mark. In addition, the simulated bite marks show that the bite marks are deeper in the lower part of the setting position. It can be proved that the establishment and analysis results of the finite element model are consistent with the experiment results.
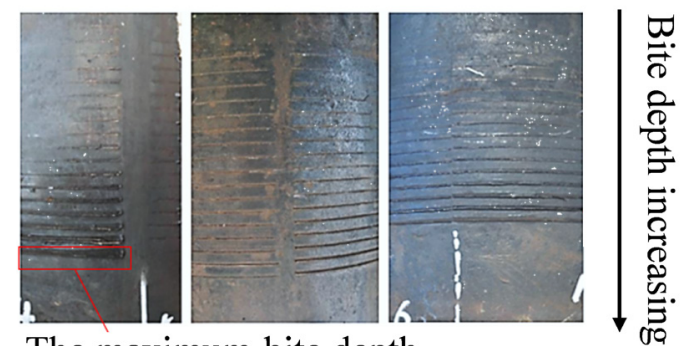

a) The maximum bite depth

b)

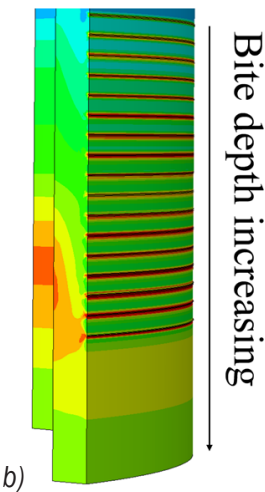

Fig. 11. a) Experiment bite marks on the casing surface; b) simulated bite marks on the casing surface

\subsection{Relationship between Bite Depth and Suspension Load}

The maximum depth of the slips bite into the casing when the suspended load is increased from $1000 \mathrm{kN}$ to $6000 \mathrm{kN}$ is simulated, as shown in Fig. 12. The maximum height of the slips bite into the casing gradually increases with the suspension load, which gradually enhances the plastic deformation of the casing surface.

When the slips bite into the casing surface, the bite depth of each tooth into the casing is different. Therefore, the teeth on the same slip are numbered sequentially from bottom to top, and the bite depth of all 17 teeth of the $\phi 273 \mathrm{~mm}$ WE-type hanger slips into the casing under different suspension loads was obtained, as illustrated in Fig. 13. 


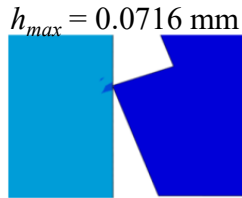

$F=1000 \mathrm{kN}$

$h_{\max }=0.2566 \mathrm{~mm}$

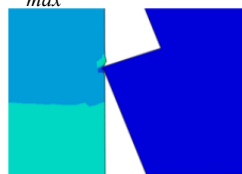

$F=4000 \mathrm{kN}$

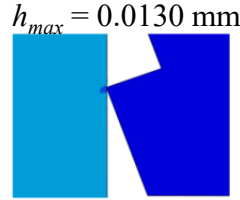

$F=2000 \mathrm{kN}$

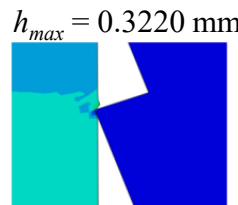

$F=5000 \mathrm{kN}$

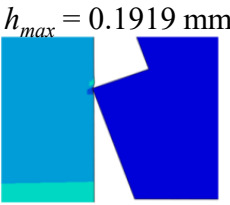

$F=3000 \mathrm{kN}$

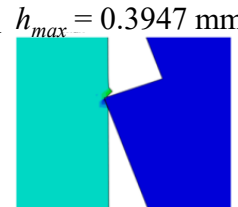

$F=6000 \mathrm{kN}$
Fig. 12. Maximum bite depth of casing surface under different suspension load

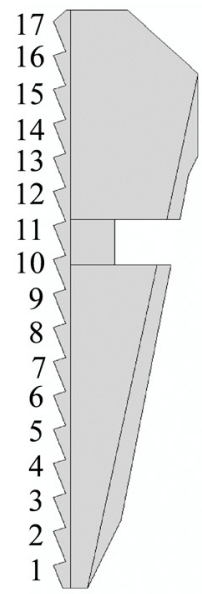

Fig. 13. Number of slip hanger's teeth

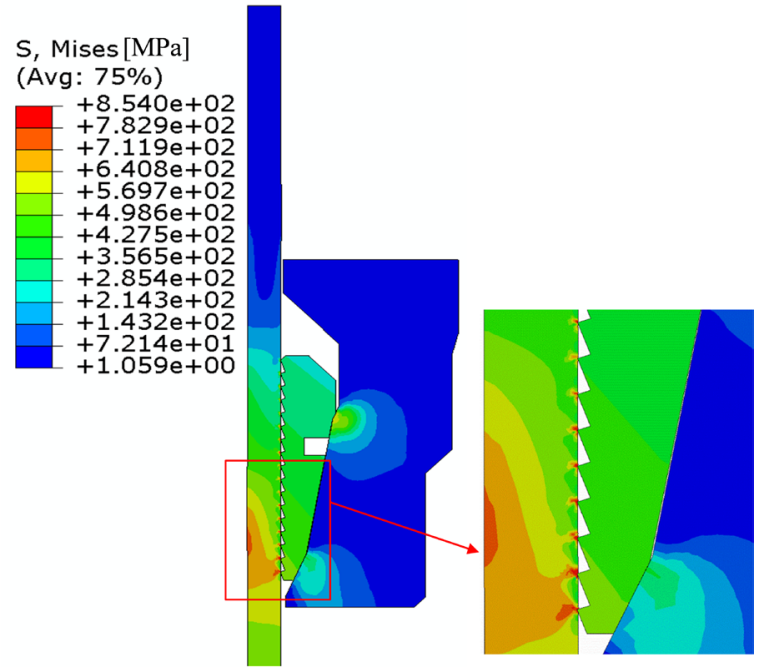

Fig. 14. Equivalent stress cloud diagram of slip teeth biting into the casing

According to Figs. 14 and 15, the bite depth of slip inserts into the casing is differentiated under the same suspension load, equivalent stress on the casing and the bite depth of slips gradually decreases from no. 1 to no. 17 (from bottom to top). With the increase of the suspension load, the bite depth of the slips gradually increases, and the increase in the bite depth of the slips is higher in the lower positions (smaller number).

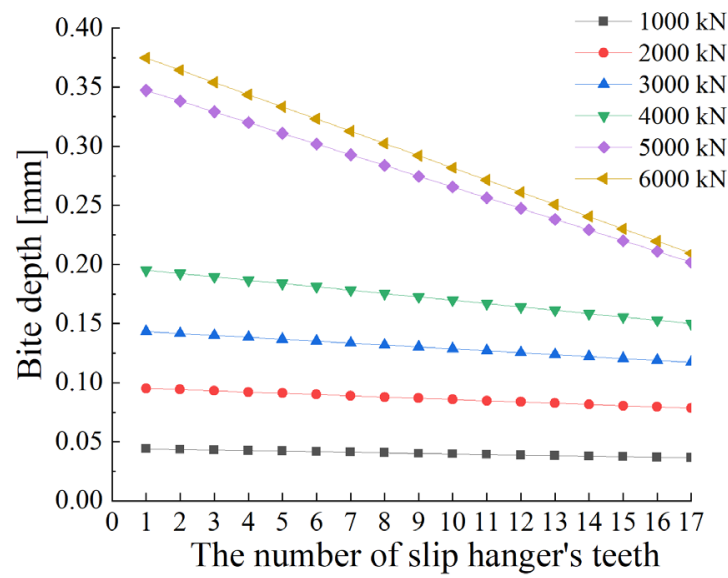

Fig. 15. Relationship between the bite depth and the number of slip hanger's teeth, and the suspension load

According to the finite element simulation results, the relationship between the suspension force and the maximum bite depth of the slip can be obtained, as shown in Fig. 16, which is used to fit the formula of the relationship between the suspension load and the maximum bite depth of the slip:

$$
h_{\max }=7 E-11 x^{3}+6 E-8 x^{2}+0.0006 x+0.0129,
$$

where $h_{\max }$ is the maximum bite depth of slips [mm]; $x$ is the suspension load $[\mathrm{kN}]$.

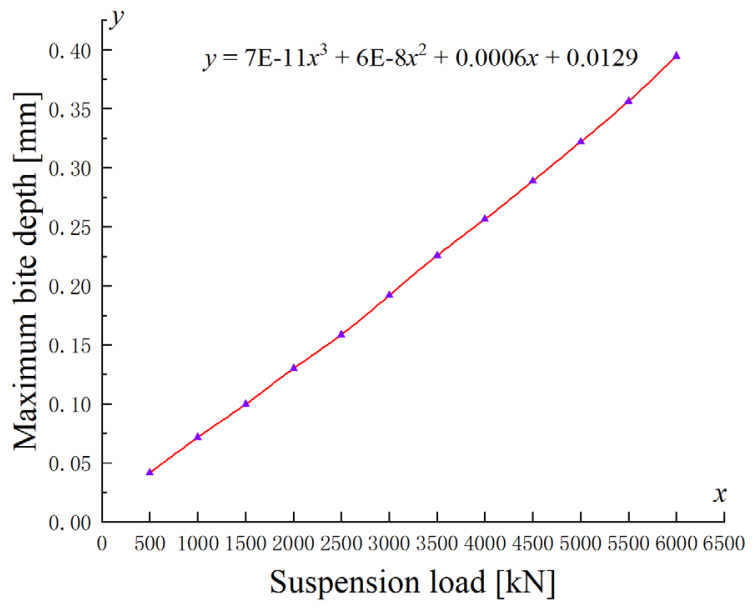

Fig. 16. Relationship between the suspension load and the maximum bite depth of slips 


\subsection{Relationship between the Suspension Load and the Residual Collapse Strength}

When the slip inserts bite into the casing, the mechanical properties of the casing varies with the bite depth of the slips, which leads to variation in the collapse strength and suspension ability of the casing. Therefore, it is of great significance to study the effect of the bite depth of slips on the collapse strength and suspension ability of the casing. The cross-sectional schematic of the slip teeth bite into the casing is shown in Fig. 17. Assuming that the suspension load of the hanger at a certain moment is $F$, the corresponding maximum height of the slip insert bite into the casing is $h_{\max }$. If the casing cross-sectional area is $A_{C}\left[\mathrm{~mm}^{2}\right]$, the residual wall thickness of the casing at the maximum bite position is $t_{s}=t-h_{\max }[\mathrm{mm}]$, the residual diameter $D_{S}=D-2 h_{\max }[\mathrm{mm}]$, and the axial tensile stress is $S a=F / A_{C}[\mathrm{MPa}]$.

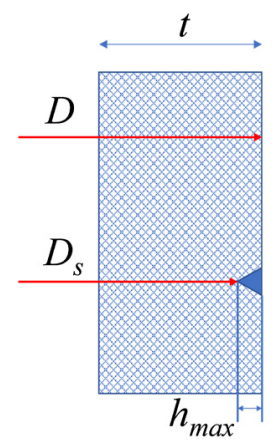

Fig. 17. Profile of bite of slip insert into the casing

The equivalent yield strength of the casing under the action of axial tensile stress is written as:

$$
Y_{p a}=\left[\sqrt{1-0.75\left(\frac{S_{a}}{Y_{p}}\right)^{2}}-0.5 \frac{S_{a}}{Y_{p}}\right] Y_{p},
$$

where $Y_{p a}$ is the equivalent yield strength of the casing under axial tensile stress $[\mathrm{MPa}], Y_{p}$ is the yield strength of the casing [MPa].

When $(D / t)_{Y P} \leq D_{S} / t_{S} \leq(D / t)_{P T}$, is combined with the API formula for plastic collapse pressure and takes the safety factor as 1.5 , the residual plastic collapse strength is written as:

$$
P_{P S}=Y_{P a}\left(\frac{A}{D_{S} / t_{s}}-B\right) / 1.5-6.894757 C,
$$

where $P_{P S}$ is residual plastic collapse strength [MPa], $(D / t)_{Y P}$ is $D / t$ limit value of yield strength collapse and plastic collapse, is the limit value of plastic collapse and elastic-plastic collapse, and casing steel grade coefficient.

The relationship between the suspension load and the residual collapse strength of the wellhead casing was obtained by integrating Eqs. (18) to (20), as shown in Fig. 18. As the suspension load increases, the casing residual collapse strength decreases. When decreases to a certain value, the maximum suspension force corresponding to the slips at a certain bite depth can be obtained. In practical application, considering the uneven wellhead or the error during installation of casing head, the residual collapse strength of the casing obtained in Fig. 18 should be divided by a "working condition factor".

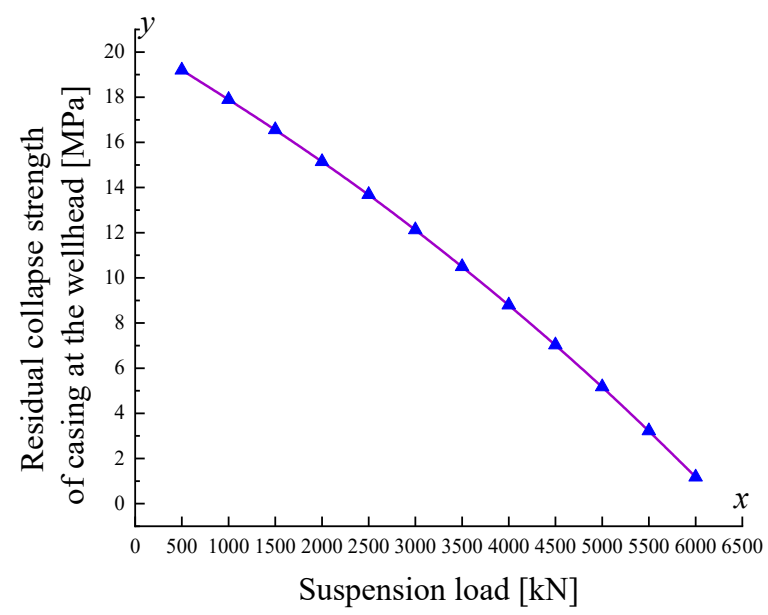

Fig. 18. Relationship between the suspension load and the residual collapse strength of casing at the wellhead

\section{CONCLUSIONS}

An axisymmetric finite element model of the hanger suspended the casing was established based on the real structure of the $\Phi 273 \mathrm{~mm}$ WE slip hanger. The accuracy of the finite element model was proved by comparing the simulation results with the real bite marks on the casing surface.

The bite depths of slip inserts into the casing are different under a specific suspension load. The bite depth of the slips is gradually reduced from no. 1 to no. 17 (from bottom to top). With the increase of the suspension load from $1000 \mathrm{kN}$ to $6000 \mathrm{kN}$, the maximum bite depth of slip inserts into the casing gradually increases from $0.07163 \mathrm{~mm}$ to $0.3947 \mathrm{~mm}$, and the increase in the bite depth of the slips is higher in the lower positions (smaller number).

As the suspension load increases, the residual collapse strength of the casing decreases. When the 
residual collapse strength decreases to a certain value, the maximum suspension force corresponding to the bite depth of slip inserts can be obtained.

\section{REFERENCES}

[1] Wen, J.L., Han, X.W., Xin, Z., Sheng, S.C. (2019). Sealing properties and structure optimization of packer rubber under high pressure and high temperature. Petroleum Science, vol. 16, no. 3, p. 632-644, D0I:10.1007/s12182-018-0296-0.

[2] Zhang, Z., Sang, P.F., Sang, Z., Hou, D., Lv, Y., Zheng, Y., Zhang, C. (2020). Analyzing failure of casing head slip hanger. Engineering Failure Analysis, vol. 108, art. ID. 104301, D0l:10.1016/j.engfailanal.2019.104301.

[3] Koc, P. (2019). An exacting wall-penetration pipe analysis. Strojniški vestnik - Journal of Mechanical Engineering, vol. 65, no. 3, p. 189-197, D0I:10.5545/sv-jme.2018.5651.

[4] Li, C., Guan, Z.C., Zhang, B., Wang, Q., Xie, H.Q., Yan, Y., Han, C. (2021). Failure and mitigation study of packer in the deep water HTHP gas well considering the temperaturepressure effect during well completion test. Case Studies in Thermal Engineering, vol. 26, art ID. 101021, D0I:10.1016/j. csite.2021.101021.

[5] Tong, S.K., Zhu, B.K., Cao, Y.P., Dou, Y.H. (2014). Analysis of the mechanical property of RTTS packer slip. China Petroleum Machinery, vol. 42, no. 2, p. 53-57, Dol:10.3969/j.issn.10014578.2014.02.013. (in Chinese)

[6] Tang, Y., Sun, p., Wang, G.R., Li, W. (2020). Analysis of pressure bearing performance and optimization of structural parameters of the slip in a compression packer. Science Progress, vol. 103, no. 1, p. 1-19, DOl:10.1177/0036850419881106.

[7] Mohammed, A.l., Oyeneyin, B., Atchison, B., Njuguna, J. (2019). Casing structural integrity and failure modes in a range of well types-A Review. Journal of Natural Gas Science and Engineering, vol. 68, art. ID 102898, D0l:10.1016/j. jngse.2019.05.011.

[8] Wang, Z.J., Deng, W.D., Lin, Z.C., Shang, X.F. (2013). Finite element analysis and structure improvements of packer slip in horizontal wells. Oil Drilling \& Production Technology, vol. 35, no. 5, p. 78-81, Dol:10.13639/j.odpt.2013.04.032. (in Chinese)

[9] Xu, R., Wojtanowicz, A.K. (2017). Pressure buildup test analysis in wells with sustained casing pressure. Journal of Natural Gas Science and Engineering, vol. 38, p. 608-620, DOI:10.1016/j.jngse.2016.12.033.

[10] Ahmed, S., Salehi, S., Ezeakacha, C.P., Catalin Teodoriu, C. (2019). Evaluation of liner hanger seal assembly and cement sheath as a dual barrier system: Implications for industry standards. Journal of Petroleum Science and Engineering, vol. 178, p. 1092-1103, DOI:10.1016/j.petrol.2019.04.017.

[11] Kiran, R., Teodoriu, C., Dadmohammadi, Y., Nygaard, R., Wood, D., Mokhtari, M., Salehi, S. (2017). Identification and evaluation of well integrity and causes of failure of well integrity barriers (A review). Journal of Natural Gas Science and Engineering, vol. 45, p. 511-526, D0l:10.1016/j. jngse.2017.05.009.

[12] Chen, Y., Xiao, G.P., Zhong, W.J., Yi, H. (2020). Investigation of mechanical numerical simulation and expansion experiment of expandable liner hanger in oil and gas completion. Shock and Vibration, vol. 2020, art. ID 9375835, DOl:10.1155/2020/9375835.

[13] Patel, H., Salehi, S., Teodoriu, C., Ahmed, R. (2019). Performance evaluation and parametric study of elastomer seal in conventional hanger assembly. Journal of Petroleum Science and Engineering, vol. 175, p. 246-254, D0I:10.1016/j. petrol.2018.12.051.

[14] Ahmed, S., Salehi, S., Ezeakacha, C. (2020). Review of gas migration and wellbore leakage in liner hanger dual barrier system: Challenges and implications for industry. Journal of Natural Gas Science and Engineering, vol. 78, p. 103284, DOI:10.1016/j.jngse.2020.103284.

[15] Al-Abri, 0.S., Pervez, T. (2013). Structural behavior of solid expandable tubular undergoes radial expansion processAnalytical, numerical, and experimental approaches. International Journal of Solids and Structures, vol. 50, no. 19, p. 2980-2994, DOI:10.1016/j.ijsolstr.2013.05.013.

[16] Meng, H., Ge, H.K., Fu, D.W., Wang, X., Shen, Y., Jinag, Z., Wang, J. (2020). Numerical investigation of casing shear deformation due to fracture/fault slip during hydraulic fracturing. Energy Science \& Engineering, vol. 8, no. 10, p. 3588-3601, Dol:10.1002/ese3.766.

[17] Zhang, Z., Shao, L.Y., Zhang, Q.S., Zhang, C., Li, J., Zeng, D., Zhong, X., Hu, J., Hou, D., Shi, T. (2017). Environmentally assisted cracking performance research on casing for sour gas wells. Journal of Petroleum Science and Engineering, vol. 118, p. 729-738, D0l:10.1016/j.petrol.2017.08.050.

[18] White, S.P., Weir, G.J., Laycock, N.J. (2000). Calculating chemical concentrations during the initiation of crevice corrosion. Corrosion Science, vol. 42, no. 4, p. 605-629, DOI:10.1016/S0010-938X (99)00097-9.

[19] Sharland, S.M. (1992). A mathematical model of the initiation of crevice corrosion in metals. Corrosion Science, vol. 33, no. 2, p. 183-201, DOI:10.1016/0010-938X (92)90144-R.

[20] Xu, Z.L. (2016). Polar solutions to plane problems. In Zhao, X.D. (ed.) Elasticity. Higher Education Press, Beijing, p. 73-77.

[21] Glenk, C., Hüter, F., Billenstein, D., Rieg, F. (2018). Consideration of body forces within finite element analysis. Strojniški vestnik - Journal of Mechanical Engineering, vol. 64, no. 5, p. 303-309, Dol:10.5545/sv-jme.2017.5081.

[22] Wang, H.L., Long, B., Yang, Y., Xiao, Y., Wang, C. (2020). Modelling the Influence of Inlet Angle Change on the Performance of Submersible Well Pumps. International Journal of Simulation Modelling, vol. 19, no. 1, p. 100-111, DOI:10.2507/IJSIMM19-1-506. 